\title{
Hidden diversity in sympatric sponges: adjusting life-history dynamics to share substrate
}

\author{
Andrea Blanquer*, María-J. Uriz, Gemma Agell \\ Centre d'Estudis Avançats de Blanes-CSIC, Accés cala St Francesc 14, 17300 Blanes-Girona, Spain
}

\begin{abstract}
Marine biodiversity is difficult to assess accurately in part because of the existence of sibling species, which are difficult to discern. This is particularly tricky when sibling species live in sympatry. We investigated biological and ecological traits in 2 sympatric sibling sponge species inhabiting the shallow north-western Mediterranean: Scopalina lophyropoda Schmidt, 1862 and S. blanensis Blanquer \& Uriz, 2008. Growth, fissions, fusions, and survival were monitored twice monthly for $2 \mathrm{yr}$. $S$. lophyropoda slightly increased in area over the $2 \mathrm{yr}$ period, whereas $S$. blanensis did not show effective growth, since gains in autumn to winter were offset by losses in spring to summer. Survival was significantly different in both species. By the end of the study (24 mo), $74 \%$ of the individuals of $S$. lophyropoda and $34 \%$ of $S$. blanensis survived. All individuals of $S$. lophyropoda and all but 5 of $S$. blanensis underwent fissions or fusions at least once during the study. The frequencies of multiple fissions and fusions were higher in $S$. blanensis than in $S$. lophyropoda. These 2 sympatric sibling species share common traits such as a high dynamism (higher than any other previously studied encrusting sponge species) and intra-species variability in growth. However, they showed contrasting ecological strategies (conservative in $S$. lophyropoda vs. opportunistic in $S$. blanensis), which favours species coexistence. This example shows for the first time how seasonality promotes the coexistence of sibling sponge species in the Mediterranean, and may represent an important step towards understanding species coexistence mechanisms.
\end{abstract}

KEY WORDS: Sibling species · Sympatry · Growth dynamics · Survival · Coexistence $\cdot$ Porifera · Scopalina $\cdot$ Seasonality

- Resale or republication not permitted without written consent of the publisher

\section{INTRODUCTION}

The study and conservation of the world's biodiversity are currently major ecological priorities. However, true species biodiversity is difficult to assess accurately in the marine realm because many habitats remain poorly explored. Sibling species, which are morphologically cryptic, are increasingly being reported in marine habitats (e.g. Knowlton 1993, Tarjuelo et al. 2001, Blanquer \& Uriz 2007, 2008, Pérez-Portela \& Turon 2008), indicating that an important part of the marine biodiversity still remains hidden. Furthermore, besides hidden diversity, misidentification of cryptic sibling species may lead to wrong conclusions in both basic and applied research by confounding reproduction periods, range of ecological and geographical distributions, or production of secondary metabolites, among others (e.g. Grassle \& Grassle 1976, Sanjuán et al. 1996, Söller et al. 2000, Sweijd et al. 2000, Ward 2000).

Molecular techniques are increasingly used to untangle cryptic species complexes, but they add little information to our understanding of the realized niche of the species (e.g. Tarjuelo et al. 2001, Blanquer \& Uriz 2007, Pérez-Portela et al. 2007) and cannot solve the problem of species misidentification in the field, in particular when these species have overlapping distributions (i.e. 'sympatry') (e.g. Knowlton \& Jackson 1994, Tarjuelo et al. 2001, De Caralt et al. 2002, LópezLegentil et al. 2005, Pérez-Portela et al. 2007, Blanquer \& Uriz 2007, 2008). When sibling species live in sympatry, studies on biology (e.g. life-history traits) and ecology (e.g. growth dynamics) are crucial to distinguish them and to understand the mechanisms underlying their coexistence. 
Sympatric sibling species offer unique opportunities to learn about coexistence mechanisms. We used as target species 2 thinly encrusting sponges, which inhabit the shallow north-western Mediterranean: Scopalina lophyropoda Schmidt, 1862 and S. blanensis Blanquer \& Uriz, 2008. Both species are morphologically cryptic and had been misidentified as S. lophyropoda, until recently, when $S$. blanensis was discovered by molecular markers (Blanquer \& Uriz 2007).

Both species share habitat in the Iberian littoral, and often live in close contact (Blanquer \& Uriz 2008). Their habitat consists of semi-sciaphilous vertical or subhorizontal rocky walls and lateral sides of big stones, close to the sandy bottom, between 4 and $25 \mathrm{~m}$ depth, usually in places with sediment re-suspension. Their habitat is fragmented, and, as a consequence, both species also share a highly patchy geographical distribution (Blanquer \& Uriz 2008). Scopalina lophyropoda is endemic to the Mediterranean, whereas up to now $S$. blanensis has only been reported from the north-western and central Mediterranean (Blanquer \& Uriz 2008).

Previous ecological studies performed on Scopalina lophyropoda (e.g. Uriz et al. 1998, Maldonado \& Uriz 1999a,b, Mariani et al. 2005, 2006) might have also included S. blanensis individuals, and, consequently, the conclusions of these studies should be considered with care.

Our aims were to ascertain how these 2 sympatric species manage to partition the available substrate and to explore mechanisms of species coexistence and maintenance of biodiversity in shallow Mediterranean assemblages. Life cycles are not always discriminative, since overlapping reproduction periods between close species have also been reported (e.g. Pérez-Portela et al. 2007, Blanquer \& Uriz 2008). In modular benthic invertebrates, other biological/ecological patterns across time can be decisive for the species to coexist. We focused on species-specific strategies to face the seasonal variation of environmental factors in the Mediterranean. For this purpose, we studied survival, growth (i.e. area gains) and shrinkage (i.e. area losses), as well as fusion and fission, in the 2 sympatric species and analyzed the possible seasonal trend of these biological events.

\section{MATERIALS AND METHODS}

Study site and species. The monitoring was carried out on the sub-littoral rocky walls in Blanes $\left(41^{\circ} 40.4^{\prime} \mathrm{N}\right.$, $2^{\circ} 48.2^{\prime}$ E). The study area consisted of parallel vertical walls facing north, between 8 and $14 \mathrm{~m}$ in depth, and separated by approximately $8 \mathrm{~m}$. In the study area both Scopalina lophyropoda and S. blanensis coexist on hard substrates. S. lophyropoda is one of the most abundant sponges in terms of surface cover in the area (Uriz et al.
1998), with individuals reaching ca. $1 \mathrm{~m}^{2}$. Individuals of $S$. blanensis, despite being abundant, are smaller in size, never exceeding $0.3 \mathrm{~m}^{2}$ (authors' pers. obs.).

A total of 19 individuals of Scopalina lophyropoda and 27 of $S$. blanensis were labelled and monitored over a 2 yr period. Monitoring was performed twice monthly from April 2004 to March 2006, although monthly data were used in the growth and shrinkage analyses for outlining general patterns. Water temperature at the depth where the sponges lived (ca. $12 \mathrm{~m}$ ) was also measured during each survey.

Growth/shrinkage measurements. Growth of encrusting colonial invertebrates (sponges, bryozoans and ascidians) has often been studied by deriving variation in area from pictures taken periodically in the field (e.g. Ayling 1983, Turon \& Becerro 1992, Coma et al. 1998, 2000, Turon et al. 1998, Garrabou 1999, Garrabou \& Zabala 2001, De Caralt et al. 2002, López-Legentil et al. 2005). The picture method is inadvisable for organisms with massive or irregular growth habits for which alternative complex methods have been proposed (e.g. Osinga et al. 1999, Abdo et al. 2006, McMurray et al. 2008), but suitable for thinly encrusting species in which area increases are directly related to biomass increases. The individuals of the 2 monitored species were thinly encrusting (ca. $2 \mathrm{~mm}$ in thickness); thus, growth and shrinkage were estimated as changes in sponge area. Initially, a total of 46 specimens were labelled and photographed over the 2 study years, although the number of individuals varied between sampling intervals because of fusion and fission events. The pictures were taken on a SONY Cyber-Shot digital camera, which was mounted on a custom-made set-up consisting of a $20 \times$ $14 \mathrm{~cm}$ frame fixed to the camera base by a $30 \mathrm{~cm}$ long metallic support, to ensure the same position and focal distance of all pictures at each time. The individuals in the pictures were outlined, and then their areas were measured using NIH Image 1.63 (developed at the US National Institutes of Health).

Monthly growth was estimated using the formula:

$$
\text { Growth }_{m}=\left(A_{m}-A_{m-1}\right) /\left(A_{m-1}\right)
$$

where $A_{m}$ and $A_{m-1}$ are the areas at month $m$ and at the previous month $(m-1)$, respectively.

Treatment of fusion and fission events. Fusions and fissions were recorded at each survey date (i.e. twice monthly). When fission occurred, the areas of the resulting isolated clone-mates were added. In the same way, when fusion occurred on a given survey date, the previously measured areas of those individuals fused were added a posteriori in order to give a single value per survey date.

The extents of the fission and the fusion events were measured using 2 descriptors: the percentage of individuals undergoing fission or fusion at each survey 
date and the number of total fusion and fission events at each survey date. When an individual split into 3 clone-mates, 2 fission events were noted; likewise, if 3 clone-mates fused, 2 fusion events were recorded, and so on. We also recorded whether the type of fission and fusion was single, double, triple, quadruple, or 'multiple' (i.e. 5 or more events).

Data analyses. A non-parametric, repeated-measures analysis of variance (ANOVAR) using a randomization procedure based on Manly (2001) was performed for comparing area variation and growth rates between species through time. It included 2-stage permutation of the data: first, individuals were randomly reassigned to the 2 species, and then readings for each individual were randomly rearranged among the observation times. The whole data series was randomized 4999 times (plus the observed one) to obtain the frequency distribution of the sum of squares for each factor and their interaction. It was then examined how extreme the observed values in this distribution were. An effect was judged to be significant when the observed sum of squares was exceeded by $<5 \%$ of the corresponding values in the randomization series. The randomization routine was written in Turbopascal Version 6.0 (Turon et al. 1998).

We analyzed the possible seasonal trend of these biological features by correlating them with water temperature. Cross-correlation analyses were performed to check for relationships between growth rates, surface area, and percentage of individuals undergoing fusions and/or fissions, and temperature, for both species. In cross-correlation, 2 series of data are lagged with respect to one another (time lags were in months in our case), and the usual Pearson coefficient is computed on the transformed series. Values of the correlation coefficient at time lag 0 are equivalent to the standard correlation coefficient. Correlations at time lag $n$ measure relationships of the values of the first series with values of the second series $n$ months earlier (negative lags) or later (positive lags).

Differences in fusion and fission events (either single or multiple) between species were analysed by $2 \times 2$ contingency tables, using the Chi-squared statistic. Survival curves of the 2 species were compared using a Wilcoxon-type test (Fox 1993). All the analyses were performed with STATISTICA 6.0.

\section{RESULTS}

\section{Growth, shrinkage and survival rates}

The course of the mean surface area with time of both species is presented in Fig. 1. The differences between species turned out to be significant by the permutation tests $(\mathrm{p}<0.001)$. Scopalina lophyropoda

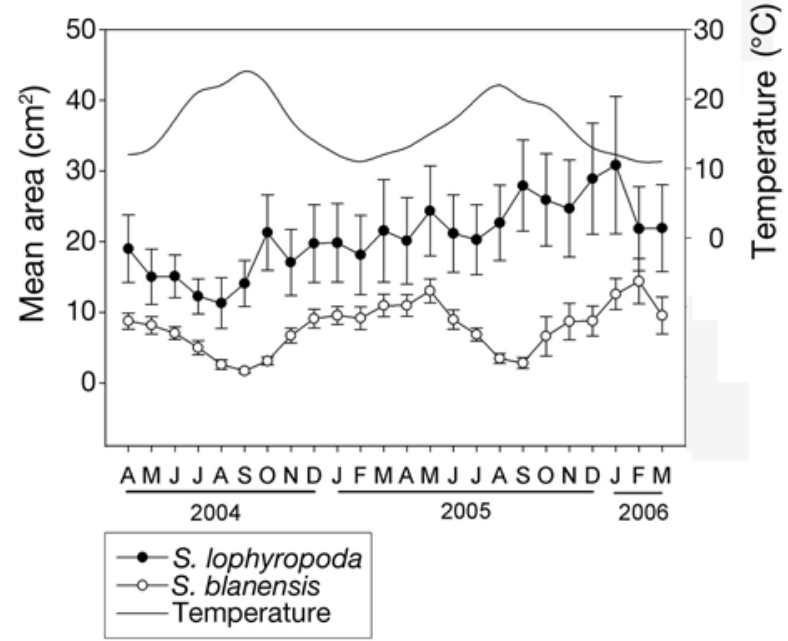

Fig. 1. Scopalina lophyropoda, S. blanensis. Mean $( \pm \mathrm{SE})$ area $\left(\mathrm{cm}^{2}\right)$ for both species. Water temperature $\left({ }^{\circ} \mathrm{C}\right)$ is also depicted

presented a slight increase in area over the 2 yr period, whereas the net variation in area of $S$. blanensis was inappreciable in the same period, since gains in autumn to winter were offset by losses in spring to summer. Moreover, the mean area of $S$. blanensis varied seasonally; it decreased from spring (April to May) to autumn (September), then it quickly recovered until the following spring.

The cross-correlation analyses between sponge area and temperature showed significant negative correlations between both parameters at time lags of +1 and +2 mo for Scopalina lophyropoda and at time lags of $+1,0,-1$ and -2 mo for $S$. blanensis (Fig. 2). This indicated that the sponge area covaried negatively with the temperature measured 1 to 2 mo later for S. lophyropoda and the temperature measured from 2 mo earlier to 1 mo later for $S$. blanensis.

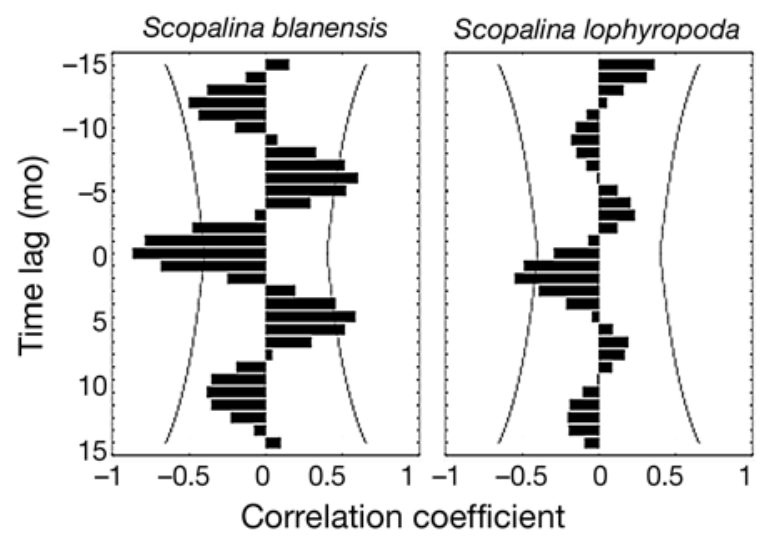

Fig. 2. Scopalina lophyropoda, S. blanensis. Cross-correlation analyses between mean area and temperature for $S$. blanensis and $S$. lophyropoda 
The patterns of growth and shrinkage rates with time for both species are presented in Fig. 3. Growth rates did not show a clear seasonal pattern in Scopalina lophyropoda, whereas they fluctuated seasonally in $S$. blanensis. All individuals of the latter species experienced shrinkage during summer, followed by significant growth in autumn (i.e. peaking in October). Growth rates were clearly higher in $S$. blanensis than in $S$. lophyropoda in autumn to early winter, while the reverse was true from spring to summer. The results of the repeated-measures ANOVAR using the randomization test on the monthly growth rates showed that the species, time and the interaction between the two were significant ( $\mathrm{p}<0.005$ in all cases).

The cross-correlation analyses also showed significant positive correlation between growth in Scopalina blanensis and temperature (at time lags of -2 or -3 mo), while no significant correlation was found in S. lophyropoda (Fig. 4).

Survival curves for both species are shown in Fig. 5. Survival was significantly different in both species (Wilcoxon test; $\mathrm{p}<0.005)$. No Scopalina lophyropoda individuals died during the first 14 mo of monitoring. In contrast, $>50 \%$ of $S$. blanensis individuals died during the same period. By the end of the study (24 mo), $74 \%$ of the individuals of $S$. lophyropoda and $34 \%$ of $S$. blanensis had survived. Mortality events in $S$. lophyropoda were concentrated in the second study year (during summer period), whereas mortality in S. blanensis was not clearly related to season.

\section{Fissions and fusions}

All individuals of Scopalina lophyropoda and all but 5 of $S$. blanensis underwent fissions and/or fusions at

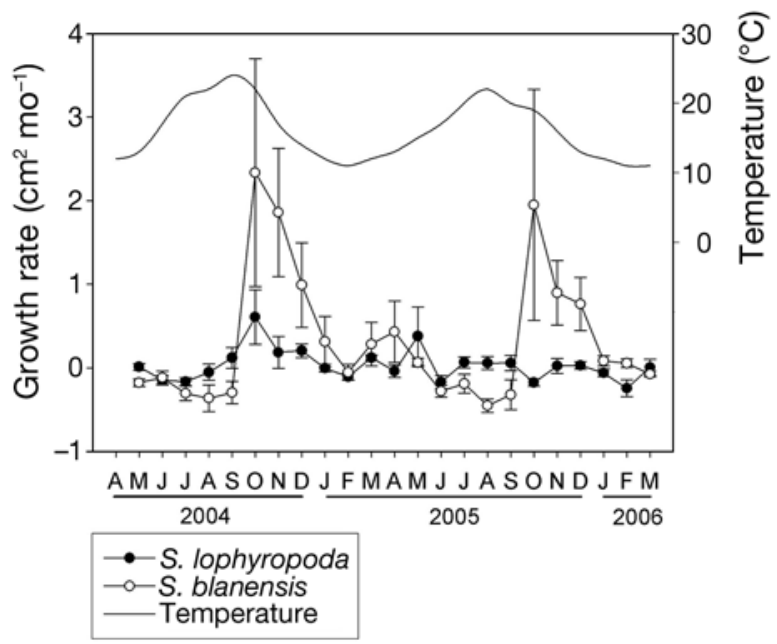

Fig. 3. Scopalina lophyropoda, S. blanensis. Mean $( \pm \mathrm{SE})$ growth rates $\left(\mathrm{cm}^{2} \mathrm{mo}^{-1}\right)$ for both species. Water temperature $\left({ }^{\circ} \mathrm{C}\right)$ is also depicted

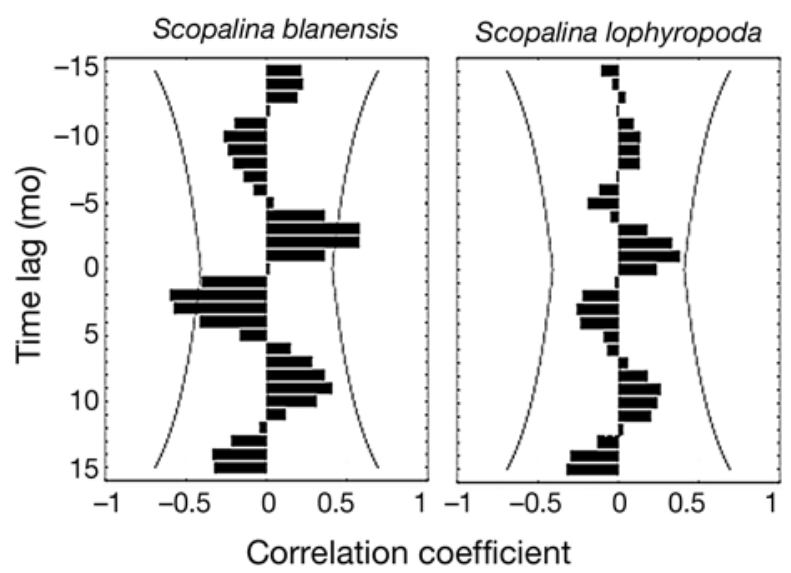

Fig. 4. Scopalina lophyropoda, S. blanensis. Cross-correlation analyses between mean growth rates and temperature for S. blanensis and S. lophyropoda

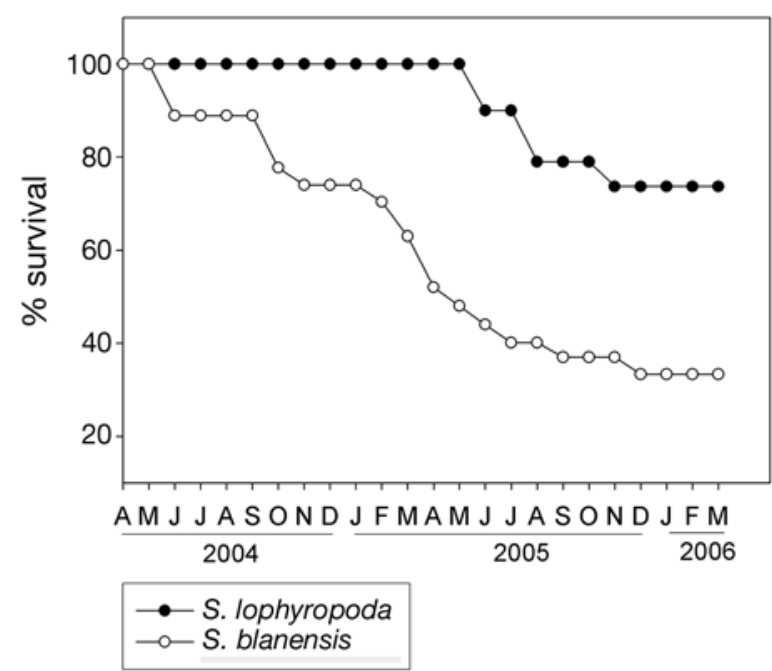

Fig. 5. Scopalina lophyropoda, S. blanensis. Survival curves for both species

least once during the study. There were totals of 109 fusions and 102 fissions in S. lophyropoda and 71 fissions and 64 fusions in S. blanensis. Percentages of individuals going through fission or fusion are shown in Fig. 6. The cross-correlation analyses between the percentage of individuals undergoing fission or fusion events and temperature revealed a significant positive relationship only for $S$. blanensis, with a time lag of 0 to -2 mo (Fig. 7). This indicated that the percentage of fused and/or divided individuals covaried positively with the temperature measured 0 to 2 mo earlier.

Percentages of single, double, triple, quadruple and multiple fission/fusion events are shown in Fig. 8. Frequencies of single fission and fusion events were significantly higher in Scopalina lophyropoda $(2 \times 2$ contingency tables, Chi-squared $\mathrm{p}<0.01$ and $\mathrm{p}<0.05$ for 


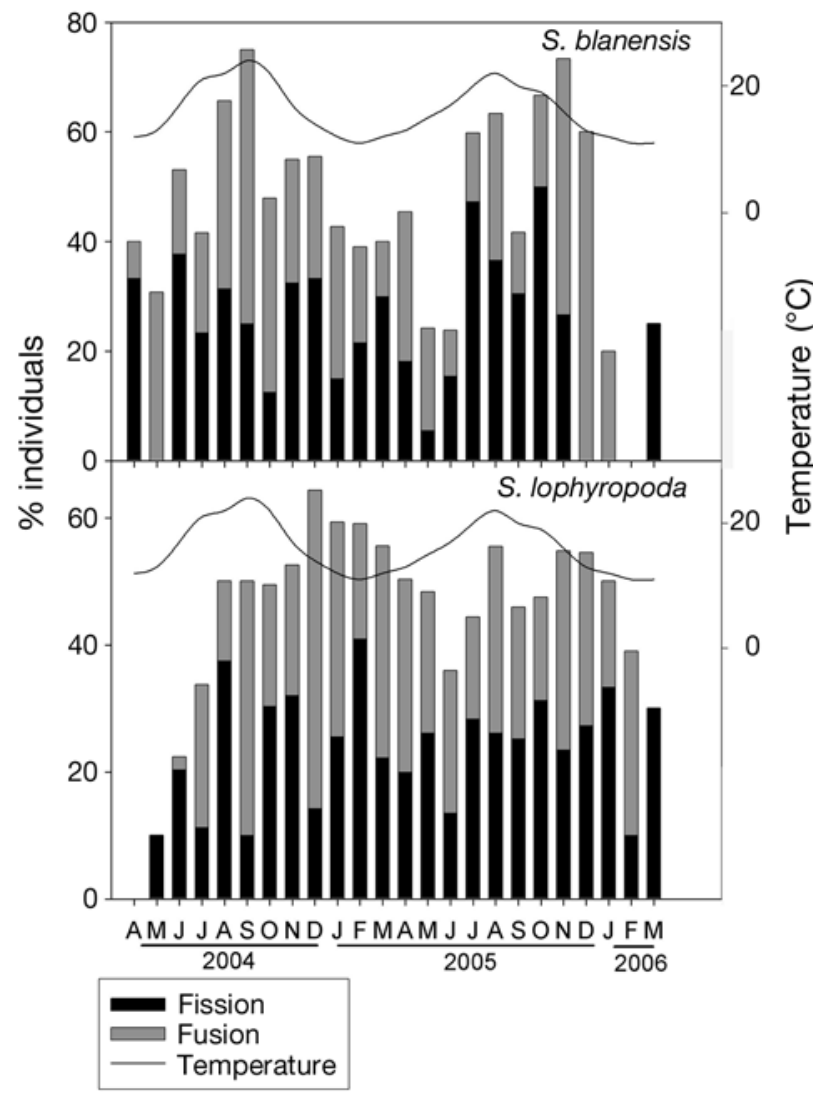

Fig. 6. Scopalina lophyropoda, S. blanensis. Percentages of individuals undergoing fission and fusion in $S$. blanensis and

S. lophyropoda. Water temperature $\left({ }^{\circ} \mathrm{C}\right)$ is also depicted

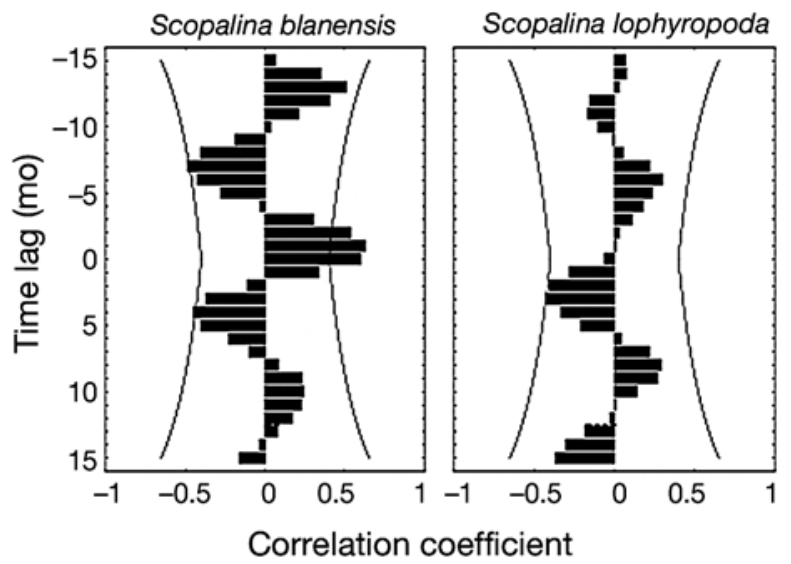

Fig. 7. Scopalina lophyropoda, S. blanensis. Cross-correlation analyses between percentages of individuals undergoing fissions or fusions and water temperature $\left({ }^{\circ} \mathrm{C}\right)$ for $S$. blanensis and $S$. lophyropoda

fissions and fusions, respectively). The frequencies of multiple fissions (i.e. resulting in 5 or more new fragments at 1 survey date) and multiple fusions (i.e. events fusing 5 or more clone-mates at 1 survey date)

\section{S. blanensis}

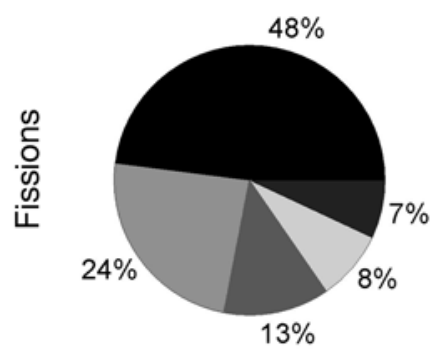

S. lophyropoda
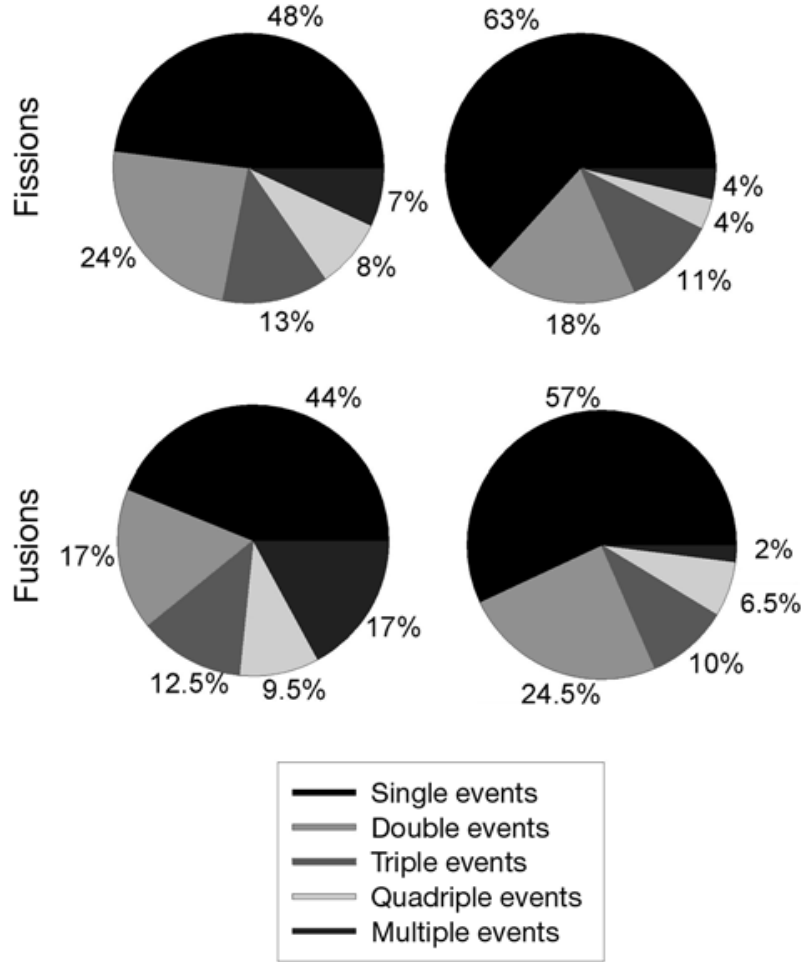

Fig. 8. Scopalina lophyropoda, S. blanensis. Types of fission and fusion events in S. blanensis and $S$. lophyropoda

were higher in $S$. blanensis than in $S$. lophyropoda $(2 \times$ 2 contingency tables, Chi-squared $\mathrm{p}<0.05$ and $\mathrm{p}<$ 0.001, for fissions and fusions, respectively).

\section{DISCUSSION}

The 2 yr monitoring revealed that the 2 Scopalina species are much more dynamic than other encrusting sponges previously studied (e.g. Fell \& Lewandroski 1981, Ayling 1983, Pansini \& Pronzato 1990, Turon et al. 1998, Garrabou \& Zabala 2001, De Caralt et al. 2008). The number of fission and fusion events (>90\% of the monitored individuals underwent fission or fusion at least once during the study) is the highest reported so far for a sponge species (cf. Ayling 1983, Pansini \& Pronzato 1990, Turon et al. 1998, Garrabou \& Zabala 2001, Tanaka 2002, De Caralt et al. 2008), in particular for $S$. blanensis, which experienced a higher number of multiple fissions and fusions than $S$. lophyropoda. The high dynamism of the 2 sponge species studied may enable them to withstand substrate competition with faster growing organisms by fragmenting and adapting their shape to the available space without decreasing their total size. 
Intra-species variability in growth rates was also high for both species (e.g. while some individuals gained area, others lost it at the same survey date), as has been reported for most sponge species studied so far (Reiswig 1973, Fell \& Lewandroski 1981, Ayling 1983, Leys \& Lauzon 1998, Turon et al. 1998, Garrabou \& Zabala 2001). Growth variability cannot be attributed to different environmental conditions in contrast to that reported for other species (e.g. Pansini \& Pronzato 1990, Bell 2002, Duckworth et al. 2004), since all the specimens studied dwelled on the same habitat. Such differences may be better explained as a response to microhabitat conditions, or to different levels of individual fitness or age (which is not necessarily correlated to size in sponges; Turon et al. 1998).

Despite Scopalina lophyropoda and $S$. blanensis both having a high and intra-species variable dynamism, the 2 species showed contrasting strategies for space acquisition and maintenance. Growth rates of S. lophyropoda were fairly constant throughout the year, only decreasing slightly in summer. In contrast, the growth rates of $S$. blanensis varied considerably during the year, with negative values in spring to summer and positive values in autumn to early winter, without appreciable net growth after 24 mo.

Mortality in Scopalina lophyropoda was unappreciable (only in the second study year) and was concentrated in summer and autumn (during and immediately after larval release; Uriz et al. 1998). Since the species shows high reproductive effort (Uriz et al. 1998, authors' pers. obs.), mortality could be related to reproductive investment. Conversely, in S. blanensis, mortality was considerably higher than that in $S$. lophyropoda, but it did not show a seasonal trend. Furthermore, larval investment was considerably lower in $S$. blanensis (authors' pers. obs.); thus, mortality in $S$. blanensis does not seem to be related to larval release (also in late summer; Blanquer \& Uriz 2008).

Seasonal fluctuations in environmental parameters (basically temperature and food availability) have been reported to strongly influence growth patterns and survival of Mediterranean benthic invertebrates (Coma et al. 2000, Coma \& Ribes 2003). Mediterranean trophic depletion in summer can cause aestivation in suspension feeders (Coma et al. 2000). Most Mediterranean sponge species, however, did not experience aestivation and also grew in summer, likely by using dissolved organic carbon (e.g. Pansini \& Pronzato 1990, Turon et al. 1998, Garrabou \& Zabala 2001), and only a few species grew preferentially in autumn to winter, when the amount of particulate food in the water was higher (Garrabou \& Zabala 2001, Coma \& Ribes 2003). Scopalina lophyropoda does not seem to suffer from summer food depletion, since it shows a constant increase in area throughout the study period.
Conversely, $S$. blanensis has a marked seasonal cycle, with negative growth rates in spring to summer (coincident with the above-mentioned trophic depletion) and significantly positive growth in autumn. The high growth rates of $S$. blanensis in autumn are interpreted here as an opportunistic response to the breakdown of the thermocline (because of the sea storms) and the consequent phytoplankton blooms (Pascual \& Flos 1984) after the summer period, when a high percentage of individuals died.

Two major conclusions can be drawn from the present study. On the one hand, these 2 sympatric cryptic species share common traits such as a high dynamism (higher than any other sponge species studied) and intra-species variability in growth, which may be related to their thinly encrusting habit that makes any change in biomass conspicuous, in particular when observed frequently (i.e. twice monthly). On the other hand, the 2 species show contrasting demographic strategies: conservative in Scopalina lophyropoda (low mortality and small but constant growth rates) versus opportunistic (fast growth when conditions are optimal and high mortality or shrinkage under adverse conditions) in $S$. blanensis, which may decrease the competition for the substrate between the 2 species. Our results support ecological theory and show that the strategy for space acquisition and maintenance significantly differed in closely related species sharing habitat.

By this example, we show for the first time how seasonality may favour the coexistence of sibling sponge species in temperate seas such as the Mediterranean by influencing their growth and mortality rates differently according to the season. The extent of this phenomenon in benthic invertebrates is still poorly known, but it may contribute to increase biodiversity in temperate seas by promoting substrate partition.

Acknowledgements. S. De Caralt and J. Sanchez-Fontenla helped with the field work. X. Turon kindly customized his program and provided statistical advice for the permutation tests. This study was funded by grants INTERGEN CTM200405265-C02-02/MAR and MARMOL CMT2007-66635-C02 from the Spanish Government (CICYT) to M.J.U. and an I3P fellowship to A.B.

\section{LITERATURE CITED}

Abdo DA, Seager JW, Harvey ES, McDonald JI, Kendrick GA, Shortis MR (2006) Efficiently measuring complex sessile epibenthic organisms using a novel photogrammetric technique. J Exp Mar Biol Ecol 339:120-133

Ayling AL (1983) Growth and regeneration rates in thinly encrusting Demospongiae from temperate waters. Biol Bull (Woods Hole) 165:343-352

Bell JJ (2002) Regeneration rates of a sublittoral demosponge. J Mar Biol Assoc UK 82:169-170

Blanquer A, Uriz MJ (2007) Sponge cryptic species revealed 
by mitochondrial and ribosomal genes: a phylogenetic approach. Mol Phylogenet Evol 45:392-397

Blanquer A, Uriz MJ (2008) 'A posteriori' searching for phenotypic characters to describe new cryptic species of sponges revealed by molecular markers (Scopalina: Dictyonellidae). Invertebr Syst 22:1-14

> Coma R, Ribes M (2003) Seasonal energetic constraints in Mediterranean benthic suspension feeders: effects at different levels of ecological organization. Oikos 101: 205-215

Coma R, Ribes M, Zabala M, Gili JM (1998) Growth in a modular colonial marine invetebrate. Estuar Coast Shelf Sci 47:459-470

- Coma R, Ribes M, Gili JM, Zabala M (2000) Seasonality in coastal benthic ecosystems. Trends Ecol Evol 15:448-453

> De Caralt S, López-Legentil S, Tarjuelo I, Uriz MJ, Turon X (2002) Contrasting biological traits of Clavellina lepadiformis (Ascidiacea) populations from inside and outside harbours in the western Mediterranean. Mar Ecol Prog Ser 244:125-137

> De Caralt S, Uriz MJ, Wijffels RH (2008) Grazing, differential size-class dynamics and survival of the Mediterranean sponge Corticium candelabrum. Mar Ecol Prog Ser 360: 97-106

> Duckworth AR, Battershill CN, Schiel DR (2004) Effects of depth and water flow on growth, survival and bioactivity of two temperate sponges cultures in different seasons. Aquaculture 242:237-250

Fell PE, Lewandroski KB (1981) Population dynamics of the estuarine sponge, Halichondria sp., within a New England eelgrass community. J Exp Mar Biol Ecol 55:49-63

Fox GA (1993) Failure-time analysis: emergence, flowering, survivorship, and other waiting times. In: Scheiner SM, Gurevitch J (eds) Design and analysis of ecological experiments. Chapman \& Hall, London

Garrabou J (1999) Life-history traits of Alcyonium acaule and Parazoanthus axinellae (Cnidaria, Anthozoa), with emphasis on growth. Mar Ecol Prog Ser 178:193-204

> Garrabou J, Zabala M (2001) Growth dynamics in four Mediterranean demosponges. Estuar Coast Shelf Sci 52: 293-303

Grassle J, Grassle JF (1976) Sibling species in the marine pollution indicator Capitella (Polychaeta). Science 192: 567-569

Knowlton N (1993) Sibling species in the sea. Annu Rev Ecol Syst 24:189-216

Knowlton N, Jackson JBC (1994) New taxonomy and niche partitioning on coral reefs: Jack of all trades or master of some? Trends Ecol Evol 9:7-9

Leys SP, Lauzon NRJ (1998) Hexactinellid sponge ecology: growth rates and seasonality in deep water sponges. J Exp Mar Biol Ecol 230:111-129

López-Legentil S, Ruchty M, Domenech A, Turon X (2005) Life cycles and growth rates of two morphotypes of Cystodytes (Ascidiacea) in the western Mediterranean. Mar Ecol Prog Ser 296:219-228

> Maldonado M, Uriz MJ (1999a) Sexual propagation by sponge fragments. Nature 398:476

Maldonado M, Uriz MJ (1999b) An experimental approach to the ecological significance of microhabitat-scale movement in an encrusting sponge. Mar Ecol Prog Ser 185:239-255

Manly FJ (2001) Randomization and Monte Carlo methods in biology. Chapman \& Hall, London
Mariani S, Uriz MJ, Turon X (2005) The dynamics of sponge larvae assemblages from northwestern Mediterranean nearshore bottoms. J Plankton Res 27:249-262

> Mariani S, Uriz MJ, Turon X, Alcoverro T (2006) Dispersal strategies in sponge larvae: integrating the life history of larvae and the hydrologic component. Oecologia 149: 174-184

McMurray SE, Blum JE, Pawlik JR (2008) Redwood of the reef: growth and age of the giant barrel sponge Xestospongia muta in the Florida Keys. Mar Biol 155:159-171

Osinga R, Redeker D, de Beukelaer PB, Wijffels RH (1999) Measurement of sponge growth by projected body area and underwater weight. Mem Qld Mus 44:419-426

Pansini M, Pronzato R (1990) Observations on the dynamics of a Mediterranean sponge community. In: Rützler K (ed) New perspectives in sponge biology. Smithsonian Institution Press, Washington, DC

Pascual J, Flos J (1984) Metereologia i oceanografia. In: Ros JD, Olivella I, Gili JM (eds) Els sistemes naturals de les Illes Medes, Vol 73. Arxius de la Secció de Ciències de l'Institut d'Estudis Catalans, Barcelona, p 75-114

Pérez-Portela R, Turon X (2008) Cryptic divergence and strong population structure in the colonial invertebrate Pycnoclavella communis (Ascidiacea) inferred from molecular data. Zoology 111:163-178

Pérez-Portela R, Palacin C, Duran S, Turon X (2007) Biological traits of three closely related species of Pycnoclavella (Ascidiacea) in the western Mediterranean. Mar Biol 152:1031-1038

Reiswig HM (1973) Population dynamics of three Jamaican demospongiae. Bull Mar Sci 23:191-226

- Sanjuán A, Pérez-Losada M, Guerra A (1996) Genetic differentiation in three Sepia species (Mollusca: Cephalopoda) from Galician waters (north-west Iberian Peninsula). Mar Biol 126:253-259

Söller R, Warnke K, Saint-Paul U, Blohm D (2000) Sequence divergence of mitochondrial DNA indicates cryptic biodiversity in Octopus vulgaris and supports the taxonomic status of Octopus minor (Cepahalopoda: Octopodidae). Mar Biol 136:29-35

Sweijd NA, Bowie RCK, Evans BS, Lopata AL (2000) Molecular genetics and the management and conservation of marine organisms. Hydrobiologia 420:153-164

Tanaka K (2002) Growth dynamics and mortality of the intertidal encrusting sponge Halichondria okadai (Demospongiae, Halichondrida). Mar Biol 140:383-389

Tarjuelo I, Posada D, Crandall KA, Pascual M, Turon X (2001) Cryptic species of Clavellina (Ascidiacea) in two different habitats: harbours and rocky littoral zones in the northwestern Mediterranean. Mar Biol 139:455-462

Turon X, Becerro MA (1992) Growth and survival of several ascidian species from the northwestern Mediterranean. Mar Ecol Prog Ser 82:235-247

Turon X, Tarjuelo I, Uriz MJ (1998) Growth dynamics and mortality of the encrusting sponge Crambe crambe (Poecilosclerida) in contrasting habitats: correlation with population structure and investment in defence. Funct Ecol 12:631-639

Uriz MJ, Maldonado M, Turon X, Marti R (1998) How do reproductive output, larval behaviour, and recruitment contribute to adult spatial patterns in Mediterranean encrusting sponges? Mar Ecol Prog Ser 167:137-148

Ward RD (2000) Genetics in fisheries management. Hydrobiologia 420:191-201
Editorial responsibility: Roger Hughes,

Bangor, UK 